\title{
Endothelial Dysfunction in Women Athletes: Integrative Review of the Literature
}

\section{Brenda Luz Lima ${ }^{1}$, Fabiana da Silva Cabral ${ }^{1}$, Suzanne Soares de Jesus $^{1}$, Kamila Souza Santana ${ }^{2}$ and Sidnei Jorge Fonseca Junior ${ }^{3 *}$}

${ }^{1}$ Graduate Student in Physical Education, UNIABEU University Center, Brazil

${ }^{2}$ Physical Education and Sports School's, UFRJ - Federal University of the Rio de

Janeiro, Brazil

${ }^{3}$ CAp-UERJ, State University of the Rio de Janeiro, Brazil

*Corresponding Author: Sidnei Jorge Fonseca Junior, Professor, CAp-UERJ, State

University of the Rio de Janeiro, Brazil.
Received: October 04, 2021

Published: November 25, 2021

(C) All rights are reserved by Sidnei Jorge

Fonseca Junior., et al.

\begin{abstract}
Endothelial dysfunction emerges as another possible component of the triad of female athletes (amenorrhea, osteoporosis and eating disorders). The objective of this study was to analyze in the scientific literature the recent information about endothelial dysfunction in women athletes of different sports modalities. Thus, an integrative literature review was carried out, with a systematic search in the PubMed databases and Virtual Health Library in 2018. Five articles were selected to integrate the discussion on endothelial dysfunction in female athletes. Studies are still very scarce, which makes scientific development with high-performance athletes more relevant and challenging. However, it was possible to observe that endothelial dysfunction should be on the agenda in the current discussions about the athlete's health because it is related to the appearance of dangerous vascular alterations. In this sense, it tends to be considered as another component of the triad of women athletes and there is a need for further studies, because apparently the prevalence of endothelial dysfunction seems to be high in sports modalities that require a low percentage of body fat with the origin of low energy availability and high training load for sports performance.
\end{abstract}

Keywords: Amenorrhea; Bone Density; Energy Intake; Eating Disorders; Physical Education and Training

\section{Abbreviations}

ACSM: American College of Sports Medicine; TWA: Triad of Women Athlete; BMD: Bone Mineral Density; VLH: Virtual Library of Health; DMF: Dilation Measured by the Flow.

\section{Introduction}

Only from 1900 was female participation in the Olympics allowed. In general, sports such as football, gymnastics and modern pentathlon are marked by prejudiced facts throughout their stories, because they are modalities considered masculine. Although the woman still fights for her rights in the sport, female participation and competition for titles and records increased [1].

Then, there is a greater concern for the athlete's health, so that the American College of Sports Medicine (ACSM) [2] published the consensus conference where the term Triad of Women Athlete (TWA) was made official because it encompasses eating disorder, amenorrhea and osteoporosis in part of high-performance sports practitioners. In addition, the ACSM [3] updated in another of its studies its definition of the triad, defining it as a spectrum of mutual relationship between the regular menstrual cycle and bone 
mineral density (BMD), which may have clinical manifestations, including eating disorders, functional hypothalamic amenorrhea and osteoporosis.

Algubut body practices such as ballet require the practitioner a lean body with a body composition of low indice in the percentage of fat. The athlete's leaner performance will facilitate the specific performance that the sport requires, making at some moments the woman who seeks performance and better results to adhere to restrictive behaviors in relation to diet, which most often may impair their performance in training and competitions, since a drastic reduction of nutrients can generate energy deficit and other nutritional disorders affecting their health [4-6].

Goolsby, and Boniquit [7] addressed the health problems that women can develop associated with the triad of female athletes, it was described the symptoms that can arise in both young and older athletes. Eating disorders end up functioning as a precursor to the beginning of the triad, because through poor diet and nutrient restrictions associated with an exhaustive routine of training and reduction of fat percentage, end up being the collaborator for the development of hormonal disorders, causing the second factor of the triad, the amenorrhea that can be classified as primary or secondary[7].

The primary amenorrhea cited by Hale [8] can be observed when the adolescent up to the age of 16 years does not have the first menstruation, even if the female secondary sexual characteristics are well defined, or even when the adolescent at the age of 14 years, has the absence not only of the first menstruation, but also of the female secondary sexual characteristics [8]. Secondary amenorrhea is characterized by menstrual cycle instability, with absence for periods of three to six months [8]. Mantonelli, Vitalle, and Amâncio [1] clarify that it can also be triggered by physical and/or psychological stress.

Another important factor in the athlete's triad is the reduction of BMD. In young athletes it occurs early due to the lack of menstrual regularity which can cause fractures and injuries mainly in the extremities of the bones in running and ballet athletes, as they are high-impact activities [1,9]. In the case of osteoporosis, once it appears, regardless of age, what can be done is palliative. The ideal is to seek prevention using an appropriate food plan and seek to make athletes aware of health risks [1].
With the advancement of studies in sports sciences and greater female participation in Sport the endothelial dysfunction emerges as another possible component of the triad of women athletes. It is a pathology that originates in the endothelium, with the layers of blood vessels undergoing changes and causing the layers of the veins to form thrombi, decreasing their diameter. Studies are still scarce, which makes scientific development with high-performance athletes more relevant and challenging. However, it is important to emphasize that the main concern is the danger of ocular cardiovascular diseases.

Initially, it seems pertinent to review the scientific information on endothelial dysfunction in women athletes of different sports modalities. In view of the above, the objective of this search was to analyze in the scientific literature the recent information about endothelial dysfunction in women athletes of different sports modalities.

\section{Methods}

The methodological procedure used to perform this work was theoretical, under a review of integrative literature pertinent to subjects involving the "athlete woman" and "endothelial dysfunction". The integrative literature review is a method that aims, in a systematic, orderly and comprehensive way, to provide broader information about a subject/problem, constituting a body of knowledge. For this purpose, this method is allowed to include studies with different methodologies, unlike the traditional systematic review that is delimited for experimental studies.

Initially, 333 abstracts involving the central theme of our research were searched between October 1 and 10, 2018, in the Databases of pubmed and 333 abstracts were found that involved the central theme of our research, to join the data contained in the Virtual Library of Health (VLH), where 351 abstracts were found that were analyzed and compared with the intention of obtaining their respective results. Two searches were performed in both databasesusing the following descriptors: "female athlete triad" individually; and the crossing of "female athlete" AND "endothelial Dysfunction".

The search process was performed by three evaluators individually, being selected one by one, after analysis of titles and abstracts of articles that addressed endothelial dysfunction in female 
athletes. After the search, the articles selected by the evaluators were analyzed in full for the final decision of those Who would participate in our study. The inclusion of articles cited during the reading of the selected materials was also considered. As an exclusion criterion, it would be adopted the non-gratuity of the articles, in addition to those that were not written in Portuguese, English or Spanish, although, at the end of the search, all were within the inclusion criteria. Figure 1 describes the search process.

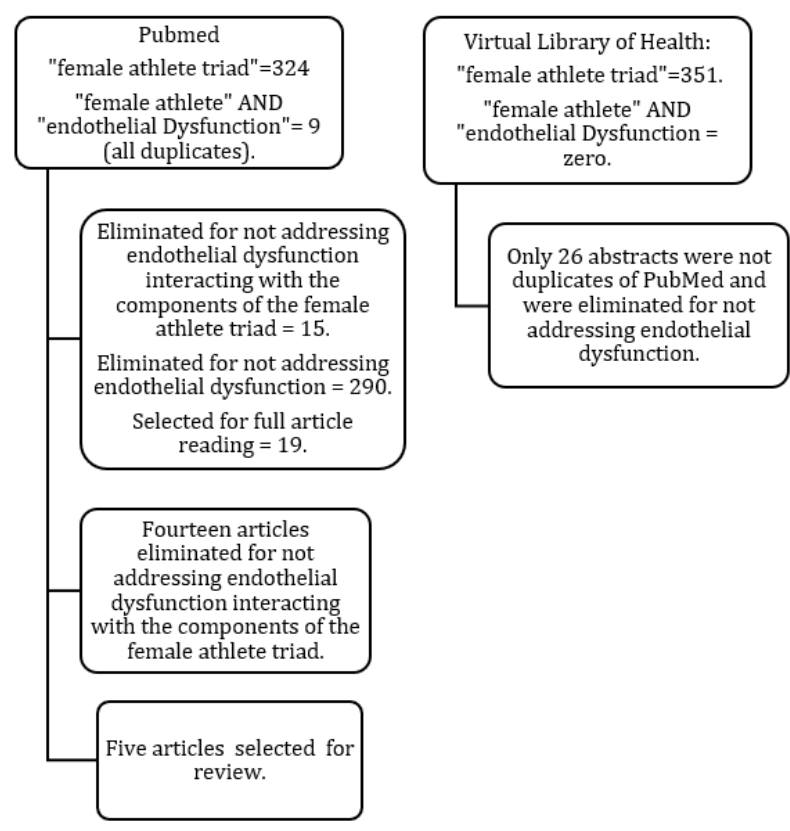

Figure 1: Flowchart of the search for articles in PubMed and Virtual Library oh Health (VLH).

\section{Results}

Table 1 describes the articles that were selected after the search for electronic data. Three were literature reviews that help in the development of the theme. A study should be highlighted by investigating the prevalence of endothelial dysfunction in a considerable number of high-performance athletes. Another demonstrates that endothelial dysfunction is associated with amenorrhea. Later it is possible to observe the main considerations of the articles found.

The study published by Hoch., et al. [10] mentions that the sports physician should have a high index of suspicion for all women ath-

\begin{tabular}{|c|c|}
\hline Authors (years) & Type of study and main objectives \\
\hline $\begin{array}{l}\text { Hoch., et al. (2007) } \\
{[10]}\end{array}$ & $\begin{array}{l}\text { Type ofand everything: Literature review. } \\
\text { The objective was to discuss disordered } \\
\text { alimentation, amenorrheia, osteoporosis and } \\
\text { the potential for increased cardiovascular } \\
\text { risk in young athletic women. }\end{array}$ \\
\hline $\begin{array}{l}\text { Lanser, Zach, and } \\
\text { Hoch (2011) [11] }\end{array}$ & $\begin{array}{l}\text { Type of study: review and literature through } \\
\text { two databases. } \\
\text { The objective was to discuss the position of } \\
\text { the ACMS in relation to the triad of women } \\
\text { athletes and the new studies that were } \\
\text { emerging in relation to the theme. }\end{array}$ \\
\hline $\begin{array}{l}\text { Zach, Machin, and } \\
\text { Hoch (2011) [12] }\end{array}$ & $\begin{array}{l}\text { Type of study: Literature review. } \\
\text { The objective to provide an update on new } \\
\text { problems related between associated } \\
\text { athletic amenorrhea and endothelial } \\
\text { dysfunction, based on several articles that } \\
\text { addressed several methodologies, on the } \\
\text { triad, including the relationship between } \\
\text { amenorrhea in athletes and endothelial } \\
\text { dysfunction. }\end{array}$ \\
\hline $\begin{array}{l}\text { Hoch., et al. (2011) } \\
{[4]}\end{array}$ & $\begin{array}{l}\text { Type of study: Cross-sectional observational. } \\
\text { The objetive was to determine the } \\
\text { prevalence of the } 3 \text { components of the } \\
\text { female athlete's triad disordered feeding, } \\
\text { menstrual dysfunction, low bone mineral } \\
\text { density (BMD) and its relationships with } \\
\text { dilation mediated by brachial artery flow in } \\
\text { professional dancers. }\end{array}$ \\
\hline $\begin{array}{l}\text { Rickenlund, } \\
\text { Eriksson, and } \\
\text { Schenck-Gustafsson } \\
\text { (2014) [13] }\end{array}$ & $\begin{array}{l}\text { Type of study: Cross-sectional observational. } \\
\text { The aim of this study was to evaluate } \\
\text { endothelial function measured as flow-me- } \\
\text { diated dilation (FMD) of the brachial artery } \\
\text { and blood markers of cardiovascular } \\
\text { diseases in young female resistance athletes } \\
\text { with menstrual disorders. }\end{array}$ \\
\hline
\end{tabular}

Table 1: Type of study and main objectives of theselectedr tigos.

letes regardless of sport, besides playing an active role in prevention and early detection. It also states that athletic amenorrhea is associated with low BMD and risk of osteoporosis. It stresses that the loss of endothelial function in athletes can accelerate the development of cardiovascular diseases. 
Hoch, Lanser, and Zach [11] addressed the physiological differences in the woman's body in relation to men, emphasizing the importance of examinations and medical care even if the woman is not an athlete. The study presents as a risk for the development of the triad, athletes who participate in sports with an emphasis on thinness. The present study also highlighted that there is several growing evidences for a possible fourth component of the triad, endothelial dysfunction.

The study published by Zach, Machin, and Hoch [12] was based on several studies by other authors who tried to understand how problems related to athletic amenorrhea could interfere in the relationship of cardiovascular events. It reinforces that a factor only of the triad should already be a cause of special attention for the risk of cardiovascular disease.

The study published by Hoch., et al. [4] data collection was performed with 22 elite dancers, demonstrating a high prevalence of the four components of the triad, and $64 \%$ had abnormal dilation mediated by brachial artery flow $(<5 \%)$. Such findings may have serious implications for cardiovascular and bone health in these dancers. It also emphasizes the importance of further studies in order to clarify the future damage that cardiovascular problems can cause in athletes of this modality.

Rickenlund, Eriksson, and Schenck-Gustafsson [13] observed endothelial dysfunction in young endurance athletes with amenorrhea, as well as changes in lipid profile. The same results were not found in a control group formed by athletes with oligamenorrhea and another of non-athletes with normal menstrual flow.

\section{Discussion}

Based on the observation of the selected articles, it seems important to reflect on the disorders involving the life of the athlete woman, and "endothelial dysfunction" is suggested as an integral part of the athlete's triad. Initially we can consider the scientific information scarce, because only one article investigated endothelial dysfunction with dancers presenting high prevalence as a procedure considered gold standard [4]. In another field study, the association of amenorrhea with endothelial dysfunction was observed in young endurance athletes [13].

Other studies helped the development of the context of endothelial dysfunction by expanding conceptual information. Among the review articles, Hoch., et al. [10] begins the discussion addressing endothelial dysfunction anticipating the risk of cardiovascular diseases in athletes or women in postmenopausal periods, considering that the triad of women athletes caused by negative energy balance, brings consequences to amenorrhea and osteoporosis, due to the reduction of estrogen. Peripheral and coronary vessels have estrogen receptors, which stimulate the production of nitric oxide, which acts as a dilator.

Lanser, Zach, and Hoch [11] made a fundamental contribution by characterizing endothelial dysfunction as a fourth component of the athlete's triad. Commonly, studies still present the three components of the triad separately $[14,15]$, howeverit is already associated with other pathologies. Schachinges., et al. [16], for example, associated endothelial dysfunction with progression to a long-term atheosclerotic disease and rates of cardiovascular events, and concern for female athletes is a new issue to be debated.

The beginning of field studies corroborates the controversy about the health of female athletes for showing a high prevalence of endothelial dysfunction in professional dancers and, mainly, for associating it with amenorrhea. This makes it necessary to follow up on other components that may cause the triad, in order to prevent these athletes from developing any vascular anomaly in the future [15]. Soon comes the importance of further studies in order to clarify the future damage that cardiovascular problems will cause in sports athletes considered at risk by thinness and low energy availability.

Regarding the evaluation resources, the studies by Ross., et al. [17] still describe the gold standard for the evaluation of endothelial function in a noninvasive way to ultrasound-brachial, which consists of a high resolution examination and can be easily used to evaluate the Dilation Measured by the Flow (DMF) of the brachial artery l, based on the percentage modification of the brachial artery diameter by means of reactive hyperemia. This resource has a high correlation with the results with validated risk markers of cardiovascular diseases.

According to Hoch., et al. [10], menopause in female athletes shows a relationship with the dilation of the endothelium of the coronary walls, it is suggested estrogen replacement, because the reposiçao of this hormone ends up improving vasodilation. Furthermore, the study by Rickenlund, Eriksson, and Schenck- 
Gustafsson [13] indicates that matrix endothelial function is associated with athletic amenorrhea. Therefore, early detection of any alteration of the endothelial walls becomes essential to preserve long-term health and longevity in young athletes with amenorrhea. Estrogen appears as a suggested use to have protective effects on the cardiovascularsystem. Considerations on the use of nitric oxide and folic acid in case of associated cardiovascular diseases also begin to be debated in the literature $[10,13]$.

The set of information obtained in this study is important because it demonstrates the need to observe the prevalence of endothelial dysfunction in high-performance athletes from other sports modalities, as is already performed with other components of the athlete's triad $[18,19]$. The barriers and difficulties of women in sport seem to be associated with important issues of physical, social and mental health.

The non-use of a strategy standardized by a specific guide in the search for articles for integrative review was an option because the theme is recent and the scientific literature has few studies, and should be considered a limitation.

\section{Conclusion}

It is concluded that endothelial dysfunction should be on the agenda in the current discussions about the athlete's health because it is related to the appearance of dangerous vascular alterations. In this sense, the component of the triad of women athletes should be better discussed. Although there is still a need for further studies in different sports modalities, the prevalence seems to be high in sports modalities that require a low percentage of body fat with the origin of low energy availability and high training load for sports performance. Studies addressing the prevention and treatment of endothelial dysfunction should be encouraged, since it is a phenomenon that precedes cardiovascular diseases.

\section{Conflict of Interest}

The authors declare that they have no conflict of interest.

\section{Bibliography}

1. Mantonelli G., et al. "Amenorrhea and Osteoporosis in Adolescent Athletes". Nutrition Journal 15.3 (2002): 319-332.

2. Yeager KK., et al. "The female athlete triad: disordered eating, amenorrhea, osteoporosis. Medicine and Science in Sports and Exercise 25.7 (1993): 775-777.
3. Nattiv A., et al. "American College of Sports Medicine Position stand The female athlete triad". Medicine and Science in Sports and Exercise 39.10 (2007): 1867-1882.

4. Hoch AZ., et al. "Association Between the Female Athlete Triad and Endothelial Dysfunction in Dancers". Clinical Journal of Sport Medicine 21.2 (2011): 119-125.

5. Elliot-Sale KJ., et al. "Endocrine Effectsof Relative Energy Deficiency in Sport". International Journal of Nutrition Exercise and Metabolism 28.4 (2018): 335-349.

6. Ackerman KE., et al. "Low Energy Availability Surrogates Correlate with Health and Performance Consequences of Relative Energy Deficiency in Sport". British Journal of Sports Medicine 2 (2017).

7. Goolsby MA and Boniquit N. "Bone Health in Athletes: The Role of Exercise, Nutrition, and Hormones". Sports Health 9.2 (2017): 108-117.

8. Hale RW. "Factors important to women engaged in vigorous physical activity". In: Strauss, R.H. Sports medicine. Philadelphia: WB Sauderes (1984): 258-263.

9. Heikura IA., et al. "Low Energy Availability is Difficult to Assess but Outcomes Have Large Impact on Bone Injury Rates in Elite Distance Athletes". International Journal of Nutrition Exercise and Metabolism 28.4 (2018): 403-411.

10. Hoch AZ., et al. "The Female Athlete Triad and Cardiovascular Dysfunction". Physical Medicine and Rehabiltation Clinical 18.3 (2007): 385-400.

11. Lanser EM., et al. "The Female Athlete Triad and Endothelial Dysfunction". American Academy of Physical Medicine and Rehabilitation 3 (2011): 458-465.

12. Zach KN., et al. "Advances in management of the female athlete triad and eating disorders". Clinical Sports Medicine 30 (2011): 551-573.

13. Rickenlund A., et al. "Amenorrhea in Female Athletes Is Associated with Endothelial Dysfunction and Unfavorable Lipid Profile.The Journal of Clinical Endocrinology and Metabolism 90.3 (2011): 1354-1359. 
14. Melin A., et al. "Energy Availability and The Female Athlete Triad in Elite Endurance Athletes". Scandinavian Journal of Medicine and Science in Sports 25.5 (2015): 610-622.

15. Gooslby MA and Boniquit N. "Bone Health in Athletes: The Role of Exercise, Nutrition, and Hormones". Sports Health 9.2 (2017): 108-117.

16. Schächinger V., et al. "Prognostic impact of coronary vasodilator dysfunction on adverse long-term outcome of coronary heart disease". Circulation 101.16 (2000): 1899-1906.

17. Ross R. "The pathogenesis of atherosclerosis: a perspective for the 1990s". Nature 362.6423 (1993): 801-809.

18. Folscher L., et al. "Ultra-Marathon Athletes at Risk for the Female Athlete Triad". Sports Medicine Open (2015): 1-29.

19. Thein-Nissenbaun JM., et al. "Menstrual Irregularity and Musculoskeletal Injury in Female High School Athletes". Journal of Athletic Training 47.1 (2012): 74-82.

Volume 4 Issue 12 December 2021

(C) All rights are reserved by Sidnei Jorge Fonseca Junior., et al. 